\title{
Rejuvenation of metallic glasses by non-affine thermal strain
}

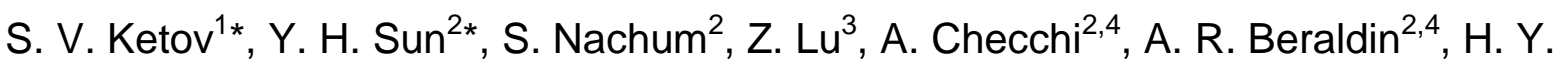 \\ $\mathrm{Bai}^{3}$, W. H. Wang ${ }^{3}$, D. V. Louzguine-Luzgin ${ }^{1}$, M. A. Carpenter ${ }^{5}$ and A. L. Greer ${ }^{1,2 \dagger}$
}

\author{
${ }^{1}$ WPI Advanced Institute for Materials Research (WPI-AIMR), Tohoku University, 2-1-1 Katahira, \\ Aoba-ku, Sendai 980-8577, Japan. \\ ${ }^{2}$ University of Cambridge, Department of Materials Science \& Metallurgy, 27 Charles Babbage Road, \\ Cambridge CB3 OFS, UK. ${ }^{\dagger}$ e-mail: alg13@cam.ac.uk \\ ${ }^{3}$ Institute of Physics, Chinese Academy of Sciences, Beijing 100080, PR China. \\ ${ }^{4}$ Department of Management and Engineering, University of Padua, 3 Stradella San Nicola, Vicenza \\ 36100 , Italy. \\ ${ }^{5}$ University of Cambridge, Department of Earth Sciences, Cambridge CB2 3EQ, UK. \\ *These authors contributed equally to this work.
}

When a spatially uniform temperature change is imposed on a solid with more than one phase, or on a polycrystal of a single, non-cubic phase (showing anisotropic expansioncontraction), the resulting thermal strain is inhomogeneous (non-affine). Thermal cycling induces internal stresses, leading to structure and property changes that are usually deleterious. Glasses are the solids that form on cooling a liquid if crystallization is avoided; they might be considered the ultimate, uniform solids, without the microstructural features and defects associated with polycrystals. Here we explore the effects of cryogenic thermal cycling on glasses, specifically metallic glasses. We show that, contrary to the null effect expected from uniformity, thermal cycling induces rejuvenation, reaching less relaxed states of higher energy. We interpret these findings in the context that the dynamics in liquids become heterogeneous on cooling towards the glass transition ${ }^{1}$ and that there may be consequent heterogeneities in the resulting glasses. For example, the vibrational dynamics of glassy silica at long wavelengths are those of an elastic continuum, but at wavelengths less than approximately three nanometres are similar to those of a polycrystal with anisotropic grains ${ }^{2}$. Thermal cycling of metallic glasses is easily applied, and gives improvements in compressive plasticity. That such effects can be achieved is attributed to intrinsic non-uniformity of the glass structure, implying a non-uniform coefficient of thermal expansion (CTE). While metallic glasses may be particularly suitable for thermal cycling, the non-affine nature of strains in glasses in general deserves further study, whether they are induced by applied stresses or by temperature change.

In glasses there are no equivalent atoms, and elastic deformation must be non-affine. For metallic glasses this has been explored through atomistic simulations $\mathrm{s}^{3,4}$ and diffraction-based 
measurements ${ }^{5,6}$ of the pair distribution function (see, for example, the review in ref. 7). Compared to their crystalline counterparts, metallic glasses have lower elastic moduli, associated with local atomic rearrangements occurring even well within the nominally elastic regime $^{8}$. While these rearrangements (shears) contribute to apparently elastic strain, they are not individually reversible ${ }^{7}$, and there is net structural change. In atomistic simulations, shear events are localized in $\sim 1 \mathrm{~nm}$ soft spots with low-frequency vibrational modes ${ }^{4}$, and can be associated with the range of density and stiffness of nearest-neighbour clusters (i.e. the shell around a central atom $)^{3,4}$.

Measurements of metallic-glass properties do not have such fine spatial resolution, but non-uniformity is still clearly detected. Strongly and weakly bonded regions have been postulated to account for $\sim 5 \mathrm{~nm}$ zones of accelerated crystallization ${ }^{9}$. The initial yield load (in nano-indentation) shows a dispersion of values associated with structural heterogeneity ${ }^{10}$. Mapping of heterogeneity by atomic-force microscopy, over areas much larger than in simulation, shows variations of energy dissipation ${ }^{11}$ and of elastic modulus $(\sim 30 \%)^{12}$ with correlation lengths of $2.5-20 \mathrm{~nm}$.

In metallic glasses under elastic loading, non-affine strains lead to local structural change; this led us to question whether thermal strains show analogous effects. In elastic deformation, the effects of non-affine strain and modulus variation are strongest for shear. For thermal expansion/contraction of a glass, however, the macroscopic strain is hydrostatic. In simulations of amorphous iron, the local shear modulus $G$ shows a relative standard deviation of $27 \%$; the local bulk modulus $B$ shows a smaller, but still substantial, value of $18 \%^{13}$. This variation is likely to be greater for the range of bonding found in a multicomponent system ${ }^{14}$. As the CTE is, other factors being constant, inversely proportional to $B^{15}$, we expect it also shows significant variation. Noting that neighbouring regions of different CTE must satisfy elastic compatibility, atomic-level shears must develop on temperature change, and given the existence of soft spots, local structural change may occur. On annealing, metallic glasses undergo thermally activated structural relaxation to states of higher density and lower enthalpy. To avoid such effects, thermal cycling in the present work is only from near room temperature $(293-343 \mathrm{~K})$ to lower temperatures, always far below the glass-transition temperature $T_{\mathrm{g}}$ near which thermal relaxation occurs (Fig. 1$)^{16}$.

\section{Figure 1 near here}

As a metallic glass is heated towards $T_{\mathrm{g}}$, there is exothermic structural relaxation (Fig. 2a). The relaxation spectrum (heat release rate as a function of temperature) can be detected by differential scanning calorimetry (DSC). While the shape of the spectrum may be of interest $^{17}$, we focus here only on the overall heat of relaxation ( $\Delta H_{\text {rel }}$, shaded areas in Fig. $2 \mathrm{~b}$ ). Changes in $\Delta H_{\text {rel }}$ have been used to characterize the effects of thermal and mechanical 
treatments on metallic glasses; for example, heavy plastic deformation (shot-peening ${ }^{17}$ ) can induce ageing (i.e. relaxation to a lower-energy state) or rejuvenation. For lanthanum (La)based metallic glasses, cycling between room temperature $(293 \mathrm{~K})$ and liquid-nitrogen temperature $\left(77 \mathrm{~K}\right.$ ) leads to increases in $\Delta H_{\text {rel }}$ i.e. rejuvenation (Fig. 2b). For melt-spun ribbons, $\Delta H_{\text {rel }}$ peaks at $\sim 10$ cycles; for bulk glass, $\Delta H_{\text {rel }}$ is smaller, peaking at $\sim 15$ cycles; in each case, the maximum increase in $\Delta H_{\text {rel }}$ is $\sim 50 \%$ relative to the as-cast sample.

We next addressed whether such changes are due to cycling, or to the time spent at $77 \mathrm{~K}$. Ribbons were held at $77 \mathrm{~K}$ for $4 \mathrm{hr}$, much longer than the sum of the times spent at $77 \mathrm{~K}$ in cycling treatments, but this 'anneal' did not give detectable change in $\Delta H_{\text {rel }}$ (Methods, Extended Data Fig. 1).

\section{Figure 2 near here}

Because surfaces respond more rapidly than interiors, sample temperature is not spatially uniform during thermal cycling; surfaces must be in tension during cooling and in compression during heating. In nano-indentation, stress cycling can harden metallic glasses $^{18}$, raising the question of whether the $\Delta H_{\text {rel }}$ changes (Fig. 2b) are due to the temperature cycling itself, or to the associated stresses. As-cast rods of $\mathrm{La}_{55} \mathrm{Ni}_{10} \mathrm{Al}_{35}$ bulk metallic glass (BMG) were subjected to RT-77K cycles at the same time as thin discs cut from the rods. As detailed in Methods, the changes in $\Delta H_{\text {rel }}$ are independent of sample size, showing that stresses generated during cycling have a negligible effect (Extended Data Fig. 2). Thermal calculations (Extended Data Table 1) suggest that the stresses themselves are negligible, consistent with this conclusion.

Many aspects of thermal cycling could be tailored: upper and lower temperatures, holding times at these temperatures, rates of cooling and heating, number of cycles. We report preliminary studies in Methods; our focus here, however, is on property changes induced by thermal cycling.

In instrumented indentation (nano-indentation) of metallic glasses ${ }^{10,18}$, initial yielding is indicated by a sharp 'pop-in' (increase in indentation depth $h$ ) on the load- $h$ curve (Extended Data Fig. 3), corresponding to shear-banding onset. Cumulative distributions of initial yield pressure $P_{\mathrm{y}}$ (Fig. 3a) for $\mathrm{La}_{55} \mathrm{Ni}_{20} \mathrm{Al}_{25}$ glass ribbon in three states permit the effects of a longer hold at $77 \mathrm{~K}$ to be compared with cycling. The median value of $P_{\mathrm{y}}, 2.98 \mathrm{GPa}$ in the ascast sample, decreases by $3 \%$ after 10 -min hold at $77 \mathrm{~K}$, and by a further $17 \%$ after $10 \mathrm{RT}$ $77 \mathrm{~K}(1 \mathrm{~min})$ cycles. After the cycling treatments the relative width $\left(1^{\text {st }}\right.$ to $9^{\text {th }}$ decile $)$ of the $P_{\mathrm{y}}$ distribution $( \pm 15 \%)$ is greater than in the as-cast sample $( \pm 7 \%)$, suggesting that cycling induces greater heterogeneity.

The corresponding distributions of hardness $H$ (Fig. 3b), determined from $h$ at full load, show similar trends. The median $H$ of the as-cast sample, $2.65 \mathrm{GPa}$, is $1 \%$ lower after $10 \mathrm{~min}$ 
at $77 \mathrm{~K}$, and a further $4 \%$ lower after $10 \mathrm{RT}-77 \mathrm{~K}$ cycles. For a given sample, the $H$ distribution is narrower than that for $P_{\mathrm{y}}$; e.g. after cycling, the relative width is only $\pm 3 \%$ (one fifth that of $P_{\mathrm{y}}$ ). Evidently $H$, reflecting conditions for continuance of flow, is much less sensitive to local heterogeneities than is $P_{\mathrm{y}}$. The Young modulus, determined on unloading, shows similar behaviour to $H$ (Extended Data Fig. 4).

The distribution curves of $P_{\mathrm{y}}$ and $H$ confirm changes related to the number of cycles rather than the holding time at $77 \mathrm{~K}$. The marked reduction in $P_{\mathrm{y}}$ induced by cycling is accompanied by a reduction in initial yield increments ( $\Delta h$, Extended Data Fig. $4 a)$.

\section{Figure 3 near here}

Metallic glasses show exceptionally high yield stress and yield strain ${ }^{19}$, and can be very tough $^{20}$, but there is a clear need to improve their plasticity. Annealing reduces their plasticity, often inducing brittleness. Figures 2 and 3 show property changes opposite to those expected from annealing, suggesting that thermal cycling gives rejuvenation. The effects on macroscopic plasticity are explored for two BMG compositions tested in uniaxial compression (Fig. 4). The plastic strain of 1.5-mm-diam. samples of $\mathrm{Zr}_{62} \mathrm{Cu}_{24} \mathrm{Fe}_{5} \mathrm{Al}_{9}$ is improved (from $4.9 \%$ to $7.6 \%$ ) by successive thermal cycles (Fig. $4 \mathrm{a}$ ). Improvements in plasticity, smaller in absolute terms (for reasons given in Methods), but larger relatively, are seen in larger-diameter samples of the same glass (Fig. 4b), which also show a reduction in microhardness (by 4\%, inset), similar to that for the median hardness of the La-based glass in Fig. 3b. $\mathrm{Cu}_{46} \mathrm{Zr}_{46} \mathrm{Al}_{7} \mathrm{Gd}_{1} \mathrm{BMG}\left(1.5 \times 1.5 \times 3.0 \mathrm{~mm}^{3}\right.$ cuboid $)$ shows an increase in plastic strain from $1.4 \%$ in the as-cast state to $5.1 \%$ after 10 RT-77K cycles (Fig. 4c). A sample fully relaxed by annealing is brittle and is not successfully rejuvenated by cycling, but a strong rejuvenation effect is possible after partial thermal relaxation, when thermal cycling gives a plastic strain similarly improved to that of as-cast samples.

\section{Figure 4 near here}

Well below $T_{\mathrm{g}}$, plastic flow in metallic glasses is localized into thin shear bands. Macroscopic plasticity is limited by premature failure on one or a few dominant shear bands. The plasticity can be improved by proliferation of shear bands, making the overall flow more uniform $^{21}$. The shear-band spacing of $\sim 10 \mu \mathrm{m}$ in the as-cast sample (Fig. $4 \mathrm{~d}$ ) is reduced to $\sim 2.5 \mu \mathrm{m}$ in the thermally cycled sample, suggesting greater ease of shear-band initiation, consistent with reductions in $P_{\mathrm{y}}$ (Fig. 3a) and in initial yield displacements (Extended Data Fig. 4a). Resonant ultrasound spectroscopy (RUS) was used to measure the elastic moduli of $\mathrm{Cu}_{46} \mathrm{Zr}_{46} \mathrm{Al}_{7} \mathrm{Gd}_{1} \mathrm{BMG}$, which show no detectable change on thermal cycling (Extended Data Fig. 5). 
Across a range of metallic-glass compositions, melt-spun and bulk, thermal cycling induces changes in properties. As the cycling is down to $77 \mathrm{~K}$, these changes can be compared with the property improvements (hardness, wear resistance) obtained by deep cryogenic treatment (DCT) of steels ${ }^{22}$. DCT, however, works through phase changes (transformation of residual austenite, precipitation of fine carbides) on holding at low temperature. In the present case, there is no discernible phase change (X-ray diffraction confirms that the samples remain fully glassy after cycling, Extended Data Fig. 6), and the effects are more analogous to those induced in single-phase polycrystalline non-cubic metals, e.g. thermal-cycling growth in uranium $^{23}$ and increased dislocation density in zirconium ${ }^{24}$. The widespread use of $\mathrm{DCT}^{25}$ does, however, suggest that cycling to cryogenic temperatures may be a practicable process.

The changes in $\Delta H_{\text {rel }}$ (Fig. 2c) show rejuvenation followed by ageing, opposing trends known in processes such as irradiation or plastic deformation which introduce both damage (raising the energy of the system) and mobility (enabling relaxation to lower energy). Shotpeening increases $\Delta H_{\text {rel }}$ in an annealed $\mathrm{BMG}$, but for an as-cast BMG even this intense plastic deformation reduces $\Delta H_{\text {rel }}{ }^{17}$. Thermal cycling increases $\Delta H_{\text {rel }}$ even for a rapidly quenched metallic glass. The maximum increase in $\Delta H_{\text {rel }}$ (Fig. 2c), $340 \mathrm{~J} \mathrm{~mol}^{-1}$, is (correcting for differing DSC heating rates) $\sim 60 \%$ of the increase in $\Delta H_{\text {rel }}$ in a $\mathrm{Zr}$-based BMG induced by 1 rotation in high-pressure torsion ${ }^{26}$, and reductions in hardness (Fig. 3b, Fig. 4b and Ref. [26]) are, pro rata, similar. The increases in $\Delta H_{\text {rel }}$ (Fig. 2c) are very similar to those seen in elastostatic loading ${ }^{27}$; it is remarkable that both these apparently mild processes give effects comparable with heavy plastic deformation, suggesting that non-affine strains in the nominally elastic regime are efficient in generating structural damage (disordering).

Although continued cycling leads to reversal in the $\Delta H_{\text {rel }}$ increase (Fig. 2c), the microhardness reduction appears to saturate (Fig. $4 \mathrm{~b}$ inset) while the plasticity continues to improve (Figs. 4a and 4b); the onset of yield (Fig. 3a) is facilitated more than general yielding (Fig. 3b) and the effect on high-frequency (MHz in RUS) macroscopic elastic moduli is negligible (Extended Data Fig. 5). These contrasts for different properties lead us to suggest that thermal cycling introduces heterogeneities (soft spots) ${ }^{4}$ that are particularly effective in initiating flow and improving plasticity, with lesser effects on the average structure of the metallic glass. That the effects (at least for $\Delta H_{\text {rel }}$, Fig. 2c) are greater in meltspun ribbon than in BMG of similar composition suggests that pre-existing heterogeneity (greater in a less relaxed metallic glass) helps cycling to introduce more heterogeneity; this is expected if, as we speculate, the effect is due to non-affine thermal strains arising from the heterogeneity itself. The present results, however, do not identify any characteristic length scale for the heterogeneity.

Rejuvenation of metallic glasses, with improved plasticity, has been achieved by elastostatic loading ${ }^{27,28}$, ion irradiation ${ }^{29}$, and plastic deformation ${ }^{21}$. In comparison with these 
methods, thermal cycling is attractive: it is non-destructive, not involving shape change; unlike an applied elastostatic stress, it is isotropic and cannot introduce anisotropy; it can be applied to any sample (thin film, ribbon or bulk) and repeated as necessary; it changes the whole sample (not just the surface as, e.g., in shot-peening or ion irradiation, or only inside shear bands); it is controllable, can be performed in-situ, induces no macroscopic residual stresses, involves strains far below the elastic limit, and induces no macroscopic plastic flow.

\section{References}

1. Ediger, M. D. Spatially heterogeneous dynamics in supercooled liquids. Annu. Rev. Phys. Chem. 51, 99-128 (2000).

2. Baldi, G., Zanatta, M., Gilioli, E., Milman, V., Refson, K., Wehinger, B., Winkler, B., Fontana, A. \& Monaco, G. Emergence of crystal-like atomic dynamics in glasses at the nanometer scale. Phys. Rev. Lett. 110, 185503 (2013).

3. Ding, J., Cheng, Y. Q. \& Ma, E. Correlating local structure with inhomogeneous elastic deformation in a metallic glass. Appl. Phys. Lett. 101, 121917 (2012).

4. Ding, J., Patinet, S., Falk, M. L., Cheng, Y. \& Ma, E. Soft spots and their structural signature in a metallic glass. Proc. Nat. Acad. Sci. 111, 14052-14056 (2014).

5. Poulsen, H. F., Wert, J. A., Neuefeind, J., Honkimäki, V. \& Daymond, M. Measuring strain distributions in amorphous materials. Nature Mater. 4, 33-36. (2005).

6. Hufnagel, T. C., Ott, R. T. \& Almer, J. Structural aspects of elastic deformation of a metallic glass. Phys. Rev. B 73, 064204 (2006).

7. Egami, T., Iwashita, T. \& Dmowski, W. Mechanical properties of metallic glasses. Metals 3, 77-113 (2013).

8. Weaire, D., Ashby, M. F., Logan, J. \& Weins, M. J. On the use of pair potentials to calculate the properties of amorphous metals. Acta Metall. 19, 779-788 (1971).

9. Ichitsubo, T., Matsubara, E., Yamamoto, T., Chen, H. S., Nishiyama, N., Saida, J. \& Anazawa, K. Microstructure of fragile metallic glasses inferred from ultrasoundaccelerated crystallization in Pd-based metallic glasses. Phys. Rev. Lett. 95, 245501 (2005).

10. Packard, C. E., Franke, O., Homer, E. R. \& Schuh, C. A. Nanoscale strength distribution in amorphous versus crystalline metals. J. Mater. Res. 25, 2251-2263 (2010).

11. Liu, Y. H., Wang, D., Nakajima, K., Zhang, W., Hirata, A., Nishi, T., Inoue, A. \& Chen, M. W. Characterization of nanoscale mechanical heterogeneity in a metallic glass by dynamic force microscopy. Phys. Rev. Lett. 106, 125504 (2011). 
12. Wagner, H., Bedorf, D., Küchemann, S., Schwabe, M., Zhang, B., Arnold, W. \& Samwer, K. Local elastic properties of a metallic glass. Nature Mater. 10, 439-442 (2011).

13. Egami, T. \& Srolovitz. D. Local structural fluctuations in amorphous and liquid metals: a simple theory of the glass transition. J. Phys. F: Met. Phys. 12, 2141-2163 (1982).

14. Mendelev, M. I., Ott, R. T., Kramer, M. J. \& Sordelet, D. J. Determining strain in amorphous alloys: Uncertainties with analyzing structural changes during deformation. J. Appl. Phys. 105, 023509 (2009).

15. Grüneisen, E. Theorie des festen Zustandes ein-atomiger Element. Ann. Physik 39, 257306 (1912).

16. Yu, H. B., Wang, W. H. \& Samwer, K. The $\beta$ relaxation in metallic glasses: an overview. Mater. Today 16, 183-191 (2013).

17. Concustell, A., Méar, F. O., Suriñach, S., Baró, M. D. \& Greer, A. L. Structural relaxation and rejuvenation in a metallic glass induced by shot-peening. Philos. Mag. Lett. 89, 831-840 (2009).

18. Packard, C. E., Homer, E. R., Al-Aqeeli, N. \& Schuh, C. A. Cyclic hardening of metallic glasses under Hertzian contacts: Experiments and STZ dynamics simulations. Philos. Mag. 90, 1373-1390 (2010).

19. Ashby, M. F. \& Greer, A. L. Metallic glasses as structural materials. Scripta Mater. 54, 321-326 (2006).

20. Demetriou, M. D., Launey, M. E., Garrett, G., Schramm, J. P., Hofmann, D. C., Johnson, W. L. \& Ritchie, R. O. A damage-tolerant glass. Nature Mater. 10, 123-128 (2011).

21. Greer, A. L., Cheng, Y. Q. \& Ma, E. Shear bands in metallic glasses. Mater. Sci. Eng. R 74, 71-132 (2013).

22. Preciado, M. \& Pellizarri, M. Influence of deep cryogenic treatment on the thermal decomposition of Fe-C martensite. J. Mater. Sci. 49, 8183-8191 (2014).

23. Ma, B. M. Nuclear Reactor Materials and Applications, Sect. 6.7.2. Thermal-cycling growth, pp. 149-151 (Van Nostrand, New York, 1983).

24. Yuan, C., Wang, Y., Sang, D., Li, Y., Jing, L., Fu, R. \& Zhang, X. Effects of deep cryogenic treatment on the microstructure and mechanical properties of commercial pure zirconium. J. Alloys Comp. 619, 513-519 (2015).

25. Kalsi, N. S., Sehgal, R. \& Sharma, V. S. Cryogenic treatment of tool materials: a review. Mater. Manufact. Proc. 25, 1077-1100 (2010).

26. Meng, F., Tsuchiya, K., Il. S. \& Yokoyama, Y. Reversible transition of deformation mode by structural rejuvenation and relaxation in bulk metallic glass. Appl. Phys. Lett. 101, 121914 (2012). 
27. Lee, S. C., Lee, C. M., Yang, J. W. \& Lee, J. C. Microstructural evolution of an elastostatically compressed amorphous alloy and its influence on the mechanical properties. Scripta Mater. 58, 591-594 (2008).

28. Ke, H. B., Wen, P., Peng, H. L., Wang, W. H. \& Greer, A. L. Homogeneous deformation of metallic glass at room temperature reveals large dilatation. Scripta Mater. 64, 966-969 (2011).

29. Magagnosc, D. J., Kumar, G., Schroers, J., Felfer, P., Cairney, J. M. \& Gianola, D. S. Effect of ion irradiation on tensile ductility, strength and fictive temperature in metallic glass nanowires. Acta Mater. 74, 165-182 (2014).

\section{Acknowledgements}

This research was supported by the World Premier International Research Center Initiative (WPI), MEXT, Japan, by NSF China and MOST 973 China, and by the Engineering and the Engineering and Physical Sciences Research Council, UK (Materials World Network project). Y.H.S. acknowledges support from a China Scholarship Council (CSC) scholarship. M. Falk, T. C. Hufnagel, E. Ma, D. Miracle and J. Orava are thanked for helpful discussions.

\section{Author contributions}

Preparation of metallic glasses was by S.K. and Z.L. The thermal-cycling treatments were performed by Y.H.S., S.K., A.R.B. and A.C.; calorimetry by Y.H.S., S.K., Z.L., A.C. and A.R.B.; nano-indentation by S.N. and A.R.B.; compression and microhardness tests by S.K., Y.H.S., A.R.B. and A.C.; X-ray diffraction by S.K. and Y.H.S.; and resonant ultrasound spectroscopy by Y.H.S., M.A.C., A.R.B. and A.C. Direction of the work was by D.V.L. (Sendai), H.Y.B. \& W.H.W. (Beijing), and A.L.G (Cambridge). A.L.G. led the project and the writing of the paper. All authors contributed to interpretation and presentation of the results.

\section{Additional information}

The authors declare no competing financial interests. Correspondence should be addressed to A.L.G. 
Figures

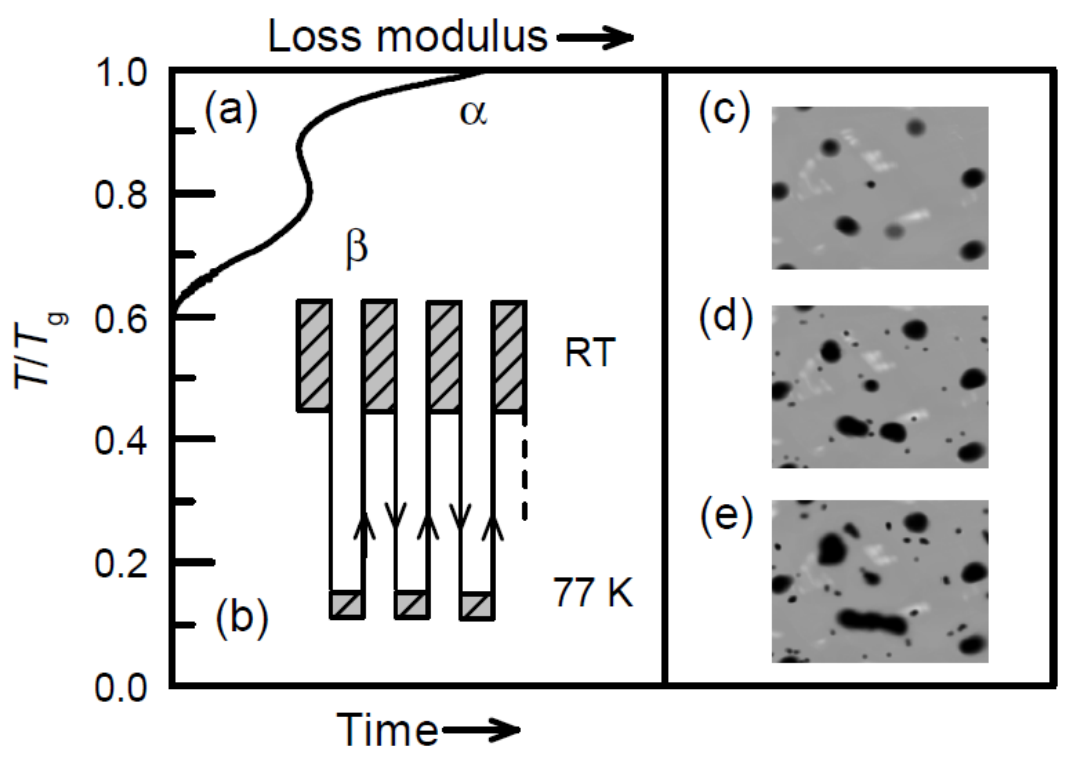

Figure 1 | Thermal cycling of metallic glasses. (a) At high fractions of the glass-transition temperature $T_{\mathrm{g}}$ to as low as $0.6 T_{\mathrm{g}}$, metallic glasses can undergo $\alpha$ and $\beta$ relaxations, giving peaks in loss modulus as a function of $T / T_{\mathrm{g}}$ as shown by the curve ${ }^{16}$. (b) The thermal cycling in the present work explores lower temperatures. Samples are cycled from near room temperature, 293-343 K, (RT) to liquid-nitrogen temperature $(77 \mathrm{~K})$. The ranges of $T / T_{\mathrm{g}}$ reflect both range of temperature and the range of $T_{\mathrm{g}}$ for the metallic glasses, from $474 \mathrm{~K}$ for $\mathrm{La}_{55} \mathrm{Ni}_{10} \mathrm{Al}_{35}$ (at.\%) up to $700 \mathrm{~K}$ for $\mathrm{Cu}_{46} \mathrm{Zr}_{46} \mathrm{Al}_{7} \mathrm{Gd}_{1}$. (c-e) Schematic depictions of the degree of heterogeneity in a metallic glass in the as-cast state (c), and after increasing numbers of thermal cycles, (d) and (e). The population and intensity of soft spots (dark), with lower elastic stiffness and higher CTE, increases with cycling. The scale of these heterogeneities is not given by the present results, but mapping of elastic properties ${ }^{11,12}$ suggests characteristic lengths of $<10 \mathrm{~nm}$. 

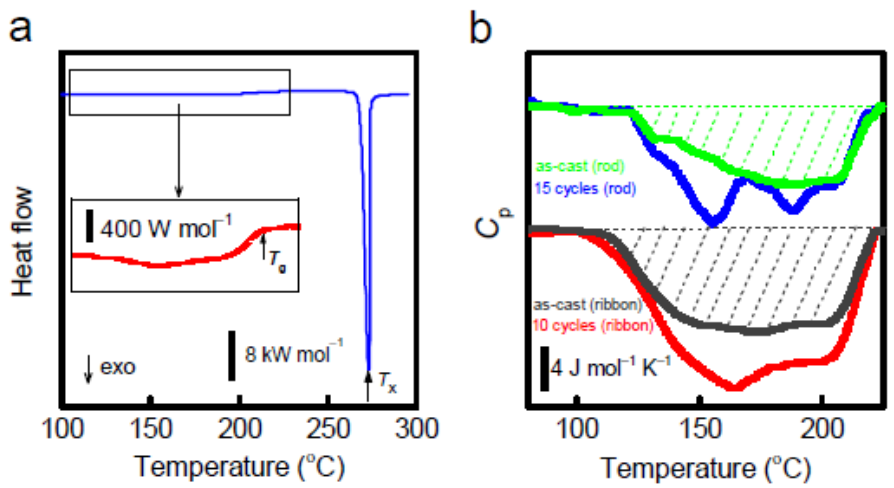

C

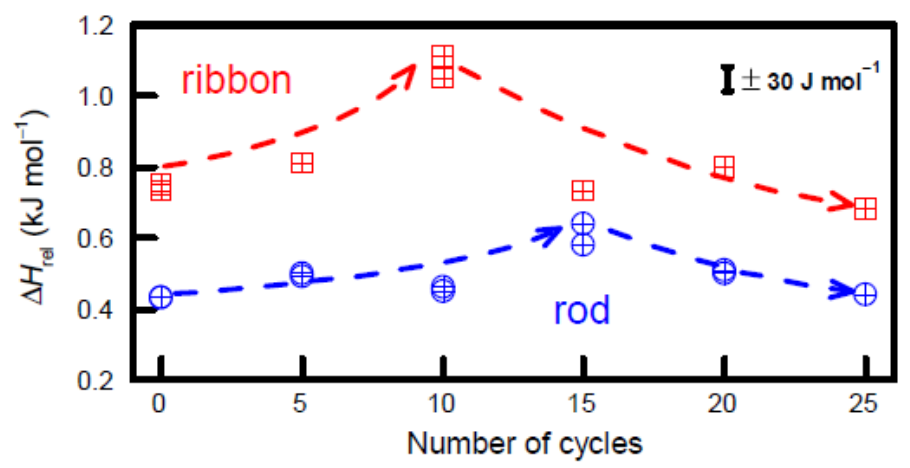

Figure 2 | Differential scanning calorimetry (DSC) of melt-spun ribbons of $\mathrm{La}_{55} \mathrm{Ni}_{20} \mathrm{Al}_{25}$ and bulk rods of $\mathrm{La}_{55} \mathrm{Ni}_{10} \mathrm{Al}_{35}$ metallic glasses. (a) DSC traces on heating show an exotherm before the glass transition at $T_{\mathrm{g}}$ (here for ribbon). (b) By subtraction of successive traces of specific heat $C_{\mathrm{p}}$ (see Methods), the heat of relaxation $\Delta H_{\text {rel }}$ associated with the exotherm can be determined (shaded areas) and is increased after RT-77K thermal cycles. (c) For ribbons, $\Delta H_{\text {rel }}$ peaks at $\sim 10 \mathrm{RT}-77 \mathrm{~K}$ cycles; for discs (250-500 $\mu \mathrm{m}$ thick) cut from the bulk rod, $\Delta H_{\text {rel }}$ is lower and peaks at 15 cycles; the data points are for individual measurements and the changes lie outside the error range of $\pm 30 \mathrm{~J} \mathrm{~mol}^{-1}$ (standard deviation estimated as in Methods). 

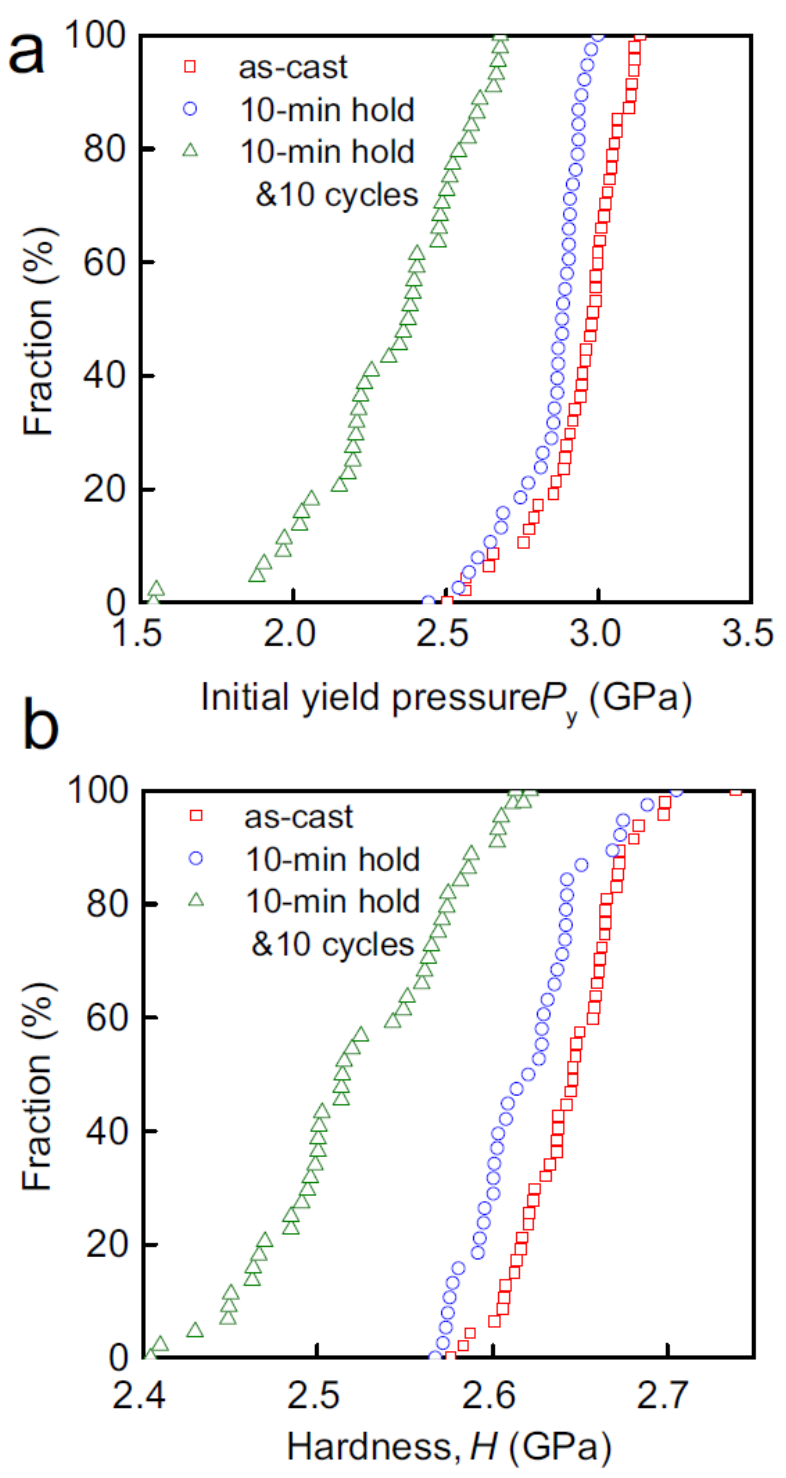

Figure 3 | Cumulative distributions of (a) initial yield pressure $\boldsymbol{P}_{\mathrm{y}}$ and (b) hardness $\boldsymbol{H}$. $\operatorname{La}_{55} \mathrm{Ni}_{20} \mathrm{Al}_{25}$ metallic glass ribbon is tested in instrumented indentation, to a maximum load of $40 \mathrm{mN}$, in 3 states: as-cast, after a 10-min hold at $77 \mathrm{~K}$, and after a further ten RT-77K cycles each with 1 min hold. The cycling reduces $P_{\mathrm{y}}$ and $H$, and widens the distribution of their values. The widening is taken to represent increasing heterogeneity of the glass structure (Fig. 1c-e). 


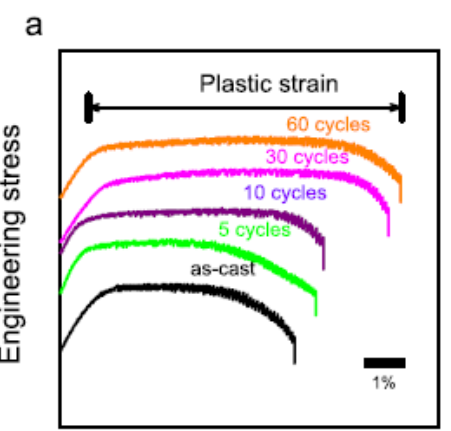

Engineering strain

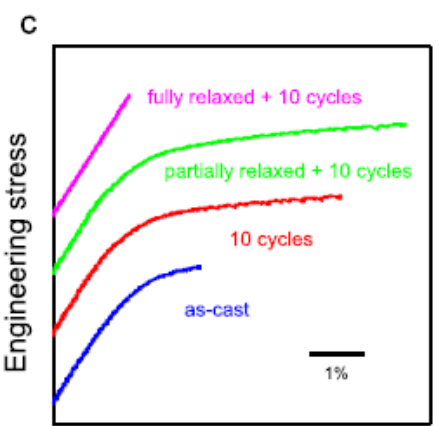

Engineering strain

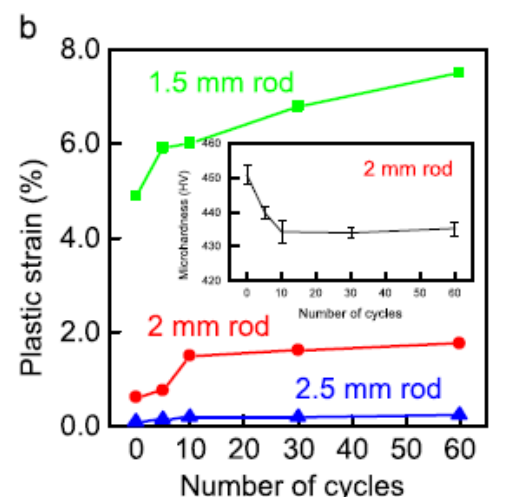

d

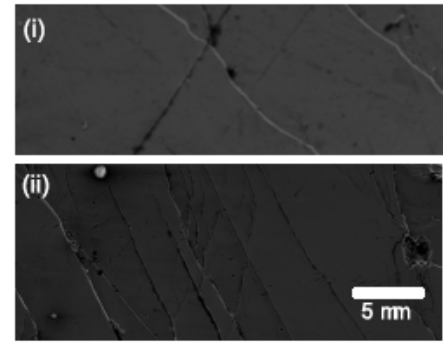

Figure 4 | Improved plasticity after thermal cycling. (a) 1.5-mm-diam. rod samples of $\mathrm{Zr}_{62} \mathrm{Cu}_{24} \mathrm{Fe}_{5} \mathrm{Al}_{9}$ BMG (yield stress $1.68 \pm 0.05 \mathrm{GPa}$ ) show an increase in plastic strain under uniaxial compression when treated with $338 \mathrm{~K}-77 \mathrm{~K}$ thermal cycles. (b) The compressive plasticity of this glass is strongly dependent on sample dimension, but for all the diameters tested, thermal cycling leads to an increase in plastic strain, accompanied (inset) by a reduction in microhardness (in $\mathrm{kg} \mathrm{mm}^{-2}$; each data point is the average of 20 measurements). (c) $1.5 \times 1.5 \times 3.0 \mathrm{~mm}^{3}$ cuboids of $\mathrm{Cu}_{46} \mathrm{Zr}_{46} \mathrm{Al}_{7} \mathrm{Gd}_{1} \mathrm{BMG}$ (yield stress $1.61 \pm 0.04 \mathrm{GPa}$ ), both as-cast and annealed $\left(1.0 \mathrm{hr}\right.$ at $\left.400^{\circ} \mathrm{C}\right)$ to partial relaxation, show an increase in plastic strain under uniaxial compression after 10 RT-77K cycles; for full relaxation (1.5 $\mathrm{hr}$ at $400^{\circ} \mathrm{C}$ ), the sample remains brittle. (d) For the $\mathrm{Cu}_{46} \mathrm{Zr}_{46} \mathrm{Al}_{7} \mathrm{Gd}_{1} \mathrm{BMG}$ samples, scanning electron microscopy shows that the population density of shear bands near the dominant shear band is lower in an as-cast sample (i) than in a similar sample tested after $10 \mathrm{RT}-77 \mathrm{~K}$ cycles (ii). 


\section{METHODS}

Metallic glasses in this study. Sample preparation and property measurements took place in three laboratories. Kinetic phenomena in glasses are best compared on a homologous temperature scale, using the glass-transition temperature $T_{\mathrm{g}}$ as the normalizing parameter. The selected glasses allow studies over a range of $T / T_{\mathrm{g}}$ : for example, room temperature (RT, $293 \mathrm{~K}$ ) covers the range of $T / T_{\mathrm{g}}=0.42-0.62$ for these glasses. (The values of $T_{\mathrm{g}}$ were determined using differential scanning calorimetry at standard heating rates of 20 and $40 \mathrm{~K}$ $\min ^{-1}$.) The four selected glasses are: (i) $\mathrm{Cu}_{46} \mathrm{Zr}_{46} \mathrm{Al}_{7} \mathrm{Gd}_{1}$ rod, $3 \mathrm{~mm}$ diameter $\left(T_{\mathrm{g}}=700 \mathrm{~K}^{30}\right.$ ); (ii) $\mathrm{La}_{55} \mathrm{Ni}_{20} \mathrm{Al}_{25}$ (at.\%) melt-spun ribbon $40 \mu \mathrm{m}$ thick $\left(T_{\mathrm{g}}=475 \mathrm{~K}\right)$; (iii) $\mathrm{La}_{55} \mathrm{Ni}_{10} \mathrm{Al}_{35}$ rod 3 mm diameter $\left(T_{\mathrm{g}}=474 \mathrm{~K}\right)$; and (iv) $\mathrm{Zr}_{62} \mathrm{Cu}_{24} \mathrm{Fe}_{5} \mathrm{Al}_{9}$ rods, 1.5 , 2.0 or $2.5 \mathrm{~mm}$ diameter $\left(T_{\mathrm{g}}=\right.$ $658 \mathrm{~K})$. Master alloys were prepared by arc-melting 3-4N pure elements. Glassy ribbons, 40 $\mu \mathrm{m}$ thick, were produced by melt-spinning, under argon atmosphere, on to a single copper wheel at 4000 revolution/min. Bulk metallic glass (BMG) rods, with diameter 1.5 to $3.0 \mathrm{~mm}$ and length up to $80 \mathrm{~mm}$, were cast, under Ti-gettered argon atmosphere, into water-cooled $\mathrm{Cu}$-moulds, using induction melting and suction casting.

Thermal cycling. The La-based and $\mathrm{Cu}_{46} \mathrm{Zr}_{46} \mathrm{Al}_{7} \mathrm{Gd}_{1}$ samples were inserted into liquid nitrogen for $1 \mathrm{~min}$, then heated by a hair-dryer set at RT, and held for $1 \mathrm{~min}$; samples were treated with up to 25 such cycles. The $\mathrm{Zr}_{62} \mathrm{Cu}_{24} \mathrm{Fe}_{5} \mathrm{Al}_{9}$ samples were inserted into liquid nitrogen for $1 \mathrm{~min}$, then into ethanol at 333-343 $\mathrm{K}$ for $1 \mathrm{~min}$; samples were treated with up to 60 such cycles.

The paper reports only results from cycling between near room temperature (RT) and liquid-nitrogen temperature $(77 \mathrm{~K})$. Keeping the upper temperature fixed (near RT), it is expected that there would be an optimum lower temperature for maximum effect of thermal cycling (at given cooling and heating rates, and hold times at the upper and lower temperatures): for higher temperatures closer to RT, there would be less driving force for structural change; for lower temperatures further from RT, the rate of structural change near the lower temperature would be lower.

In addition to cycling down to $77 \mathrm{~K}$, melt-spun ribbons of $\mathrm{La}_{55} \mathrm{Ni}_{20} \mathrm{Al}_{25}$ glass were cycled down to dry-ice $\left(\mathrm{CO}_{2}\right)$ temperature $(195 \mathrm{~K})$ and to liquid-helium temperature $(4.2 \mathrm{~K})$ to explore the role of the lower temperature. The state of the samples was assessed using DSC (with heating rates from 20 to $40 \mathrm{~K} \mathrm{~min}^{-1}$ ). For a given type of sample, the heat of relaxation $\Delta H_{\text {rel }}$ is lower for higher heating rate; it is therefore appropriate to normalize the $\Delta H_{\text {rel }}$ values relative to that for the as-cast glass measured at the same DSC heating rate. Measurements were made for samples: (i) held at $195 \mathrm{~K}$ for $100 \mathrm{~min}$, for which the ratio of $\Delta H_{\text {rel }}$ to that of the as-cast glass is 1.23 ; (ii) treated with 10 cycles of $1 \mathrm{~min}$ at $195 \mathrm{~K}$, for which the ratio is 1.24; (iii) treated with 10 cycles of $10 \mathrm{~min}$ at $195 \mathrm{~K}$ (ratio = 1.02); (iv) treated with 10 cycles of $1 \mathrm{~min}$ at $77 \mathrm{~K}$ (ratio = 1.55); and (v) treated with 13 cycles to $4.2 \mathrm{~K}$ (ratio is 1.37 ). Given the low number of samples tested, there is significant uncertainty in these relative values 
$( \pm 15 \%)$; nevertheless, it seems that, within the limited range of these tests, cycling down to $77 \mathrm{~K}$ produces the strongest effect.

A Ti-based BMG cycled up to 400 times between $77 \mathrm{~K}$ and $423 \mathrm{~K}$ (to simulate conditions on the surface of a spacecraft in low earth orbit) showed slight relaxation rather than rejuvenation ${ }^{31}$. This suggests that there is a significant annealing effect during the holds (25 min each) at the upper temperature, which itself is somewhat higher than in our work (and corresponds to $T / T_{\mathrm{g}}=0.68$, inside the range associated with $\beta$ relaxation, see Fig. 1a in main text).

Stresses associated with thermal cycling. As noted in the paper, it is important to understand whether the effects of thermal cycling are due to the temperature changes themselves or to stresses arising from non-uniform temperature in the samples during cooling and heating. Whether the temperature is significantly non-uniform can be assessed using the dimensionless Biot number,

$$
\mathrm{Bi}=\frac{h L}{\kappa},
$$

where $h$ is the heat-transfer coefficient between the sample and the surrounding medium, $L$ is a characteristic sample dimension (usually taken to be the ratio of sample volume to surface area), and $\kappa$ is the thermal conductivity of the sample material. For a flat plate $L$ is the halfthickness; for a cylinder the half-radius. If $\mathrm{Bi}<0.1$, the temperature differences within the sample are negligible compared to the step in temperature between the sample and its surroundings (Newtonian cooling). Conversely if $\mathrm{Bi}>1$, there are significant temperature gradients in the sample. We examine the conditions for samples immersed in liquid nitrogen.

Cooling in liquid nitrogen has been widely studied, particularly in connection with cryopreservation $^{32}$. The "French straw" sample containers used are cylinders of $2.8 \mathrm{~mm}$ diameter, and so are very similar in dimension to the cast BMG rods in the current work. On first immersion, there is film-boiling, in which a film of vapour limits the heat transfer; in this regime $^{32} h=148 \mathrm{~W} \mathrm{~m}^{-2} \mathrm{~s}^{-1}$. As the sample cools, there is a transition to the nucleate-boiling regime $^{32}$ in which $h=1355 \mathrm{~W} \mathrm{~m}^{-2} \mathrm{~s}^{-1}$. The transition point has been measured for a variety of metallic samples of geometry comparable to the samples in the present work $^{32}$; it occurs at temperatures ranging from 150 to $100 \mathrm{~K}$. Thus a room-temperature sample immersed in liquid nitrogen spends around $75 \%$ of the temperature range down to $77 \mathrm{~K}$ with the relatively poor heat transfer associated with the film-boiling regime.

We use materials parameters determined for Vitreloy 1; Zr-based BMGs of this kind are among those for which thermal-cycling treatments might be put into practice. For Vitreloy 1 , the thermal conductivity decreases with decreasing temperature ${ }^{33}$ and starts to level off below RT. At $300 \mathrm{~K}, \kappa=4.59 \mathrm{~W} \mathrm{~K}^{-1} \mathrm{~m}^{-1}$; we use a rough estimate of $\kappa=4 \mathrm{~W} \mathrm{~K}^{-1} \mathrm{~m}^{-1}$ for the 
temperature range in the present work. Extended Data Table 1 gives the estimates of Bi for the various sample geometries of interest.

We can see that for nearly all of these cases, $\mathrm{Bi}<0.1$, and therefore temperature gradients (and thermal stresses) in the samples are negligible. Only for the largest-diameter cylinders in the final (nucleate-boiling) stages of cooling is there any significant deviation from Newtonian cooling. These calculations support the experimental work (Extended Data Fig. 2 and associated discussion, see below) suggesting that sample size is not a significant factor in the thermal-cycling effect, and reinforce the conclusion that the effect is due to the temperature changes themselves and not due to any stresses arising from non-uniform temperature profiles in samples during cooling and heating.

It is of interest to consider the possible extent of thermal stresses associated with nonuniform sample temperature. Taking the value ${ }^{34}$ determined for the Zr-based BMG Vitreloy 106, the linear coefficient of thermal expansion is $\alpha=8.7 \times 10^{-6} \mathrm{~K}^{-1}$. For a roomtemperature sample immersed in liquid nitrogen, the maximum possible temperature difference during cooling is between $293 \mathrm{~K}$ (room temperature, possible at the sample centre) and $77 \mathrm{~K}$ (possible at the sample surface). For this temperature difference, the linear thermal strain is $0.19 \%$, which would give internal stresses of the order of $10 \%$ of the macroscopic yield stress. In practice, as highlighted by the low values for the Biot number in Extended Data Table 1, any thermal stresses would be much lower than this value. Rejuvenation of metallic glasses by elastostatic loading ${ }^{28}$ typically involves much higher stresses (up to $95 \%$ of the yield stress) for much longer times (tens of hours, rather than a few minutes). Again, it seems that stress effects in the current thermal cycling should be negligible.

Differential scanning calorimetry. This was performed (as in Fig. 2) using a Q2000 DSC (TA Instruments). Samples were heated at $20 \mathrm{~K} \mathrm{~min}^{-1}$ from $\mathrm{RT}$ to $503 \mathrm{~K}$ (into the supercooled liquid state), held for 2 minutes, then cooled to $\mathrm{RT}$ at $20 \mathrm{~K} \mathrm{~min}^{-1}$. A second cycle using the same procedure was used as the baseline for subtraction from the first cycle. The heat of relaxation $\Delta H_{\text {rel }}$ is calculated from the area between the two curves, from the onset of relaxation to the glass transition ${ }^{35}$. Additional data were acquired using a Perkin Elmer DSC 8500 at a heating rate of $40 \mathrm{~K} \mathrm{~min}^{-1}$.

Extended Data Fig. 1a shows examples of DSC traces used to assess the reproducibility of measurements of the heat of relaxation $\Delta H_{\text {rel }}$ (using the baseline-subtraction method outlined above). Six samples of as-cast ribbons were tested, giving an average value of $\Delta H_{\text {rel }}$ $=740 \mathrm{~J} \mathrm{~mol}^{-1}$, with a standard deviation of $30 \mathrm{~J} \mathrm{~mol}^{-1}$ (i.e. $\pm 4 \%$ ).

As noted in the paper, it is important to know whether the effects of thermal cycling between near room temperature and $77 \mathrm{~K}$ are due just to the time spent at $77 \mathrm{~K}$. Samples of $\mathrm{La}_{55} \mathrm{Ni}_{20} \mathrm{Al}_{25}$ glassy ribbons were held at $77 \mathrm{~K}$ for $4 \mathrm{hr}$ (a time much longer than the total spent at $77 \mathrm{~K}$ in the course of $10 \mathrm{RT}-77 \mathrm{~K}$ cycles). Within experimental error (Extended Data Fig. 1b), such holds at $77 \mathrm{~K}$ appear to have no effect on $\Delta H_{\text {rel }}$. Of course, a hold at $77 \mathrm{~K}$ 
represents a single cycle. As shown by the nano-indentation results in Fig. 3 in the main paper, even one cycle can have a measurable effect on properties. In the present case of $\Delta H_{\text {rel }}$, however, any change as a result of one cycle is within the experimental uncertainty.

As noted in the main paper and discussed above in the Methods, it is necessary to examine whether the effects of thermal cycling are dependent on sample size. The nonuniform temperature in a larger sample could give rise to stresses and the cycling of those stresses could have effects. As-cast rods ( $3 \mathrm{~mm}$ diam.) of $\mathrm{La}_{55} \mathrm{Ni}_{10} \mathrm{Al}_{35} \mathrm{BMG}$ were subjected to RT-77K cycles at the same time as thin $(250-500 \mu \mathrm{m}$ thick) discs pre-cut from the rods. After cycling, discs were cut from the centres of the bulk rods, so that samples of the same glass and same DSC-sample size could be compared after thermal cycling in two different geometries (thin disc and bulk). Extended Data Fig. 2 shows that the changes in $\Delta H_{\text {rel }}$ are essentially the same for the samples thermally cycled in disc and in bulk form, suggesting that the stresses generated during cycling have a negligible effect. The two sets of data are combined in Fig. 2c.

Instrumented indentation. This was performed using an XP Nanoindenter (MTS Systems Corp.) at room temperature under load control up to a maximum load $\left(F_{\max }\right)$ of $40 \mathrm{mN}$. A diamond spherical indenter of tip radius $8.074 \mu \mathrm{m}$ was used, its area function calibrated using fused silica and sapphire standards. Loading and unloading rates were $0.5 \mathrm{mN} \mathrm{s}^{-1}$; the drift rate was maintained below $0.07 \mathrm{~nm} \mathrm{~s}^{-1}$. Samples were loaded to $F_{\max }$, then unloaded to $0.05 F_{\max }$ and maintained at that load for $60 \mathrm{~s}$ for measurement of thermal drift. The cumulative distribution curves (Fig. 3) include 39-48 data points. Initial yield events (popins) were identified directly from the $F-h$ curve and the associated spike in indenter tip velocity, or from the first deviation from the Hertzian elastic solution fitted to the $F-h$ curve. Hardness was determined by the standard Oliver and Pharr method ${ }^{36}$, on unloading at $F_{\max }$.

Tests were conducted on melt-spun ribbons of $\mathrm{La}_{55} \mathrm{Ni}_{20} \mathrm{Al}_{25}$ glass under the conditions noted above. Typical load-displacement curves (Extended Data Fig. 3) show pop-ins (i.e. the transition from purely elastic to elastic-plastic deformation) with a moderate sharpness that is not affected by thermal cycling. The pop-ins are characterized by the values of initial yield load $F_{\mathrm{y}}$ and initial yield displacement $\Delta h$. Initial yield pressure $P_{\mathrm{y}}$ is calculated from:

$$
P_{\mathrm{y}}=\frac{F_{\mathrm{y}}}{\pi a_{\mathrm{y}}^{2}},
$$

where $a_{\mathrm{y}}$ is the contact radius at initial yield. The reduced or indentation modulus $E_{\mathrm{r}}$ is determined by the standard method ${ }^{36,37}$, on unloading from $F_{\max } . E_{\mathrm{r}}$ is also determined by using the Hertzian elastic solution to fit the shape of the load-displacement curve up to the first pop-in. $E_{\mathrm{r}}$ is given by ${ }^{38}$ : 


$$
\frac{1}{E_{\mathrm{r}}}=\frac{\left(1-v_{\mathrm{i}}^{2}\right)}{E_{\mathrm{i}}}+\frac{\left(1-v^{2}\right)}{E},
$$

where $E$ and $v$ are respectively the Young modulus and Poisson ratio of the glass, while the corresponding values $^{36}$ for the diamond indenter tip are taken to be $E_{\mathrm{i}}=1141 \mathrm{GPa}$ and $v_{\mathrm{i}}=0.07$. Using Eq. (3), values of $E$ were obtained.

Tests were conducted on ribbon samples in three states: (i) as-cast, (ii) after one cycle from RT to a 10-min hold $77 \mathrm{~K}$ and back to RT, and (iii) after a further 10 cycles to $77 \mathrm{~K}$ each with 1 min hold. The effect of a longer hold at $77 \mathrm{~K}$ can thus be compared with cycling. All metallic-glass samples, as-cast or treated, are found to have some variation in properties over length scales of $\mathrm{mm}$. For this reason it is important to compare data taken from a given region of the sample surface. In the present work, indentations were made in the same region (within $200 \mu \mathrm{m}$ ) of the given sample surface in the three successive states. Extended Data Table 2 collects data on the instrumented-indentation tests in the present work. Cumulative distributions, such as those shown in Fig. 3 in the main paper, are characterized by the median value and by the $1^{\text {st }}$ and $9^{\text {th }}$ deciles.

Extended Data Figure 4a shows the distribution of values of initial yield pressure $P_{\mathrm{y}}$ and initial yield displacement $\Delta h$ for the three states of the $\mathrm{La}_{55} \mathrm{Ni}_{20} \mathrm{Al}_{25}$ glass ribbons. On cycling, both $P_{\mathrm{y}}$ and $\Delta h$ are reduced. There is a correlation, as expected, between higher values of $P_{\mathrm{y}}$ and higher values of $\Delta h$. The spread in values of $\Delta h$ is particularly wide. After 10 RT-77K cycles, there is a marked reduction in the incidence of larger values: the initial yield events are smaller, reflecting less catastrophic shear-banding.

The Young modulus of the glass $E$ determined by unloading from full load (Extended Data Fig. 4b) shows similar effects to those found for hardness $H$ (Fig. 3b). The median value of $E_{\text {unload }}$ in the as-cast sample decreases by $0.6 \%$ after 10 -min hold at $77 \mathrm{~K}$ (compared to a $0.9 \%$ decrease in $H$ ), and by a further $7 \%$ after $10 \mathrm{RT}-77 \mathrm{~K}(1 \mathrm{~min})$ cycles (compared to $4 \%$ for $H)$. After the cycling treatments the relative width $\left(1^{\text {st }}\right.$ to $9^{\text {th }}$ decile) of the $E$ distribution $( \pm 2.4 \%$, compared to $\pm 3.1 \%$ for $H)$ is greater than in the as-cast sample $( \pm 1.4 \%$, compared to $\pm 1.3 \%$ for $H$ ).

The Young modulus determined from the Hertzian fit of the $F-h$ curve up to the first pop-in (Extended Data Fig. 4c) has a median value $~ 5 \%$ lower than that determined by unloading. The median value of $E_{\mathrm{Hertz}}$ in the as-cast sample decreases by $2.4 \%$ after 10 -min hold at $77 \mathrm{~K}$, and by a further $8.8 \%$ after $10 \mathrm{RT}-77 \mathrm{~K}(1 \mathrm{~min})$ cycles. The relative width of the $E_{\text {Hertz }}$ distribution in the as-cast sample $( \pm 1.6 \%)$ is similar to that for $E_{\text {unload }}$, but this width increases more (to $\pm 7.3 \%$ ) after the cycling treatments. This suggests that the elastic properties up to the first pop-in are more sensitive to local variations in the sample.

Compression tests. These were made on Instron 5581 and Hounsfield $25 \mathrm{kN}$ machines, loading at a strain rate of $5 \times 10^{-4} \mathrm{~s}^{-1}$. The $\mathrm{Zr}_{62} \mathrm{Cu}_{24} \mathrm{Fe}_{5} \mathrm{Al}_{9}$ samples were cylindrical rods of 
2:1 height:diameter, with diam. of $1.5,2.0$ or $2.5 \mathrm{~mm}$. The $\mathrm{Cu}_{46} \mathrm{Zr}_{46} \mathrm{Al}_{7} \mathrm{Gd}_{1}$ samples were $1.5 \times 1.5 \times 3.0 \mathrm{~mm}^{3}$ cuboids cut from the original cast rod of $3 \mathrm{~mm}$ diam. All samples were polished to a mirror finish. The gradients of the elastic portions of the stress-strain curves in Fig. $4 \mathrm{a}$ are affected by the machine compliance and underestimate the Young modulus. The curves are used only to extract values for the plastic strain as shown. The curves in Fig. 4c are almost fully corrected for machine compliance effects.

The curves in Fig. 4a and Fig. 4c show engineering stress and engineering strain. The strain values are calculated from the displacement of the testing machine and not from strain gauges on the samples. The gradients of the elastic portions of the curves are therefore affected by the machine compliance and significantly underestimate the Young modulus of the materials. The curves are used only to extract values for the plastic strain before catastrophic failure. Figure $4 \mathrm{~b}$ collects data for rod samples of $\mathrm{Zr}_{62} \mathrm{Cu}_{24} \mathrm{Fe}_{5} \mathrm{Al}_{9} \mathrm{BMG}$ of three diameters: $1.5 \mathrm{~mm}, 2.0 \mathrm{~mm}$ and $2.5 \mathrm{~mm}$, and corresponding heights $3.0 \mathrm{~mm}, 4.0 \mathrm{~mm}$ and 5.0 $\mathrm{mm}$. The stress-strain curves for $1.5 \mathrm{~mm}$ samples are shown in Fig. 4a, those for $2.0 \mathrm{~mm}$ and $2.5 \mathrm{~mm}$ samples in Extended Data Fig. 7.

As has been much discussed ${ }^{21,39}$, larger samples are more susceptible to catastrophic failure through shear localization. Such size effects are extrinsic, and relate only to the mechanical tests themselves. In addition, there is an intrinsic effect: larger samples have a lower cooling rate during casting and so are more relaxed and tend to be more brittle in the as-cast state.

Resonant ultrasound spectroscopy. RUS measurements were conducted as in earlier work $^{40,41}$. Measurements were at RT on $1.5 \times 1.5 \times 3.0 \mathrm{~mm}^{3}$ cuboids cut from the as-cast 3mm-diam. rod of $\mathrm{Cu}_{46} \mathrm{Zr}_{46} \mathrm{Al}_{7} \mathrm{Gd}_{1}$ BMG. For each sample a resonance spectrum was collected in the range $0.05-2.0 \mathrm{MHz}$ with 65,000 data points. To detect changes in shear and bulk modulus, $10 \mathrm{k}$ data points were collected in each case in the ranges $0.900-0.910 \mathrm{MHz}$ and $0.978-0.982 \mathrm{MHz}$ respectively. Within experimental error (less than $\pm 0.1 \%$ for the shear modulus), RT-77K thermal cycling has no effect on the elastic moduli of the glass (Extended Data Fig. 5). This suggests that the reductions in Young modulus (Extended Data Fig. 4b,c) and correspondingly hardness (Fig. 3b) seen under quasistatic conditions are largely attributable to anelastic (i.e. time-dependent elastic) strains.

Dynamic mechanical analysis. This technique (not discussed in the paper), permitting measurement of the loss and storage moduli of a material, was applied (using methods reported earlier ${ }^{42}$ ) to ribbons of $\mathrm{La}_{55} \mathrm{Ni}_{20} \mathrm{Al}_{25}$ glass (Extended Data Fig. 8) to explore the nature of the rejuvenation effect. The loss modulus shows a sharp maximum near the glass transition, associated with $\alpha$ relaxation. After ten RT-77K cycles, the maximum is lowered by $2.3 \mathrm{~K}$. This earlier onset of softening on heating is consistent with a rejuvenated state. The broad maximum at lower temperature (centred around $115^{\circ} \mathrm{C}$, Extended Data Fig. 8) shows $\beta$ relaxation. The $\beta$ relaxation in metallic glasses has been linked to mechanical 
properties $^{42,43}$. In view of the improved plasticity seen after thermal cycling (Fig. 4, Extended Data Fig. 7), it is surprising that the effect of thermal cycling on the $\beta$ relaxation is so slight (inset in Extended Data Fig. 8), especially compared to the clear effect on the $\alpha$ relaxation.

X-ray diffraction. There are reports that under cyclic mechanical loading at RT, in the elastic regime, a Zr-based BMG can undergo some crystallization ${ }^{44}$. Deep cryogenic treatment of steels certainly induces phase changes ${ }^{22,25}$. In the present work, X-ray diffraction (Bragg-Brentano geometry, Bruker D8 instrument, $\mathrm{Cu} \mathrm{K} \alpha$ radiation) was used to check that the samples remained fully glassy throughout, and especially after thermal cycling. Representative diffractograms for ribbon and bulk samples are shown in Extended Data Fig. 6. We found no evidence for any crystallization induced by the thermal-cycling treatments. The property changes suggest that the cycling does induce changes in the glassy structure but, typical of such structural relaxation, these changes are too subtle to be detectable with the simple X-ray methods used in the present work.

Other methods. Microhardness was measured on Akashi MVK-HVL hardness testing machine, with 20 measurements for each data point. Scanning electron microscopy (secondary-electron imaging) was performed using a JEOL 5200 instrument.

\section{References}

30. Wang, W. H. Roles of minor additions in formation and properties of bulk metallic glasses, Prog. Mater. Sci. 52, 540-596 (2007).

31. Wang, X., Shao, Y., Gong, P. \& Yao, K. F. The effect of simulated thermal cycling on thermal and mechanical stability of a Ti-based bulk metallic glass. J. Alloys. Comp. 575, 449-454 (2013).

32. Victoria Santos, M., Sansinena, M., Chirife, J. \& Zaritzky, N. Determination of heat transfer coefficients in plastic French straws plunged in liquid nitrogen. Cryobiology 69, 488-495 (2014).

33. Yamasaki, M., Kagao, S., Kawamura, Y. \& Yoshimura, K. Thermal diffusivity and conductivity of supercooled liquid in $\mathrm{Zr}_{41} \mathrm{Ti}_{14} \mathrm{Cu}_{12} \mathrm{Ni}_{10} \mathrm{Be}_{23}$ metallic glass. Appl. Phys. Lett. 84, 4653-4655 (2004).

34. Conner, R. D., Choi-Yim, H. \& Johnson, W. L. Mechanical properties of $\mathrm{Zr}_{57} \mathrm{Nb}_{5} \mathrm{Al}_{10} \mathrm{Cu}_{15.4} \mathrm{Ni}_{12.6}$ metallic glass matrix particulate composites. J. Mater. Res. 14, 3292-3297 (1999).

35. Méar, F. O., Lenk, B., Zhang, Y. \& Greer, A. L. Structural relaxation in a heavily coldworked metallic glass, Scripta Mater. 59, 1243-1246 (2008).

36. Oliver, W. C. \& Pharr, G. M. An improved technique for determining hardness and 
elastic modulus using load and displacement sensing indentation experiments, J. Mater. Res. 7, 1564-1583 (1992).

37. Field, J. S. \& Swain, M. V. A simple predictive model for spherical indentation. J. Mater. Res. 8, 297-306 (1993).

38. Johnson, K. L., Contact Mechanics (Cambridge University Press, Cambridge, 1985).

39. Cheng, Y. Q., Han, Z., Li, Y. \& Ma, E. Cold versus hot shear banding in bulk metallic glass. Phys. Rev. B 80, 134115 (2009).

40. McKnight, R. E. A., Moxon, T., Buckley, A., Taylor, P. A., Darling, T. W. \& Carpenter, M. A. Grain size dependence of elastic anomalies accompanying the alphabeta phase transition in polycrystalline quartz. J. Phys. Condens. Matter 20, 075229 (2008).

41. Concustell, A., Godard-Desmarest, S., Carpenter, M. A., Nishiyama, N. \& Greer, A. L. Induced elastic anisotropy in a bulk metallic glass. Scripta Mater. 64, 1091-1094 (2011).

42. Yu, H. B., Shen, X., Wang, Z., Gu, L., Wang, W. H. \& Bai, H. Y. Tensile plasticity in metallic glasses with pronounced $\square$ relaxations. Phys. Rev. Lett. 108, 015504 (2012).

43. Yu, H. B., Samwer, K., Wang, W. H. \& Bai, H. Y., Chemical influence on $\beta$ relaxations and the formation of molecule-like metallic glasses, Nature Comm. 4, 2204 (2013).

44. Churyumov, A. Yu, Bazlov, A. I., Zadorozhnyy, V. Yu., Solonin, A. N., Caron, A. \& Louzguine-Luzgin, D. V. Phase transformations in Zr-based bulk metallic glass cyclically loaded before plastic yielding. Mater. Sci. Eng. A 550, 358-362 (2012). 


\section{Extended Data}

Extended Data Table 1 | Values of the Biot number Bi for immersion in liquid nitrogen of the various sample geometries in the present work. The film-boiling regime applies until the sample surface temperature decreases to between $150 \mathrm{~K}$ and $100 \mathrm{~K}$, and the nucleate-boiling regime applies thereafter.

\begin{tabular}{lccc}
\hline Sample geometry & $L(\mu \mathrm{m})$ & Bi, film boiling & Bi, nucleate boiling \\
\hline melt-spun ribbon, 40 بm thick & 20 & $7.4 \times 10^{4}$ & $6.8 \times 10^{3}$ \\
disc, 250-500 $\mu$ m thick & $125-250$ & $(4.6-9.2) \times 10^{-3}$ & $(4.2-8.5) \times 10^{-2}$ \\
cylinder, $1.5 \mathrm{~mm}$ diam. & 375 & $1.4 \times 10^{-2}$ & 0.13 \\
cylinder, $2.0 \mathrm{~mm}$ diam. & 500 & $1.8 \times 10^{-2}$ & 0.17 \\
cylinder, $2.5 \mathrm{~mm}$ diam. & 625 & $2.3 \times 10^{-2}$ & 0.21 \\
cylinder, $3.0 \mathrm{~mm}$ diam. & 750 & $2.8 \times 10^{-7}$ & 0.26 \\
\hline
\end{tabular}

Extended Data Table 2 | Summary of instrumented-indentation tests. Cumulative distributions, such as those shown in Fig. 3 in the main paper, are characterized by the median value and by the $1^{\text {st }}$ and $9^{\text {th }}$ deciles.

\begin{tabular}{|l|r|r|r|r|r|r|r|r|r|}
\hline \multicolumn{1}{|c|}{ State } & \multicolumn{3}{c|}{ as-cast } & \multicolumn{3}{c|}{10 min LN } & \multicolumn{3}{c|}{10 min \& 10 cycles LN } \\
Property & $10 \%$ & median & $90 \%$ & $10 \%$ & median & $90 \%$ & $10 \%$ & \multicolumn{3}{c|}{ median $90 \%$} \\
\hline No. of indents & \multicolumn{3}{|c|}{48} & \multicolumn{3}{c|}{39} & \\
\hline$F_{y}(\mathrm{mN})$ & 10.57 & 14.35 & 16 & 10.57 & 13.51 & 14.26 & 5.82 & 9.33 & 11.46 \\
\hline$\Delta h(\mathrm{~nm})$ & 5.1 & 8.23 & 11.36 & 3.56 & 6.8 & 10.66 & 3.16 & 4.53 & 6.46 \\
\hline$P_{\mathrm{y}}(\mathrm{GPa})$ & 2.7 & 2.98 & 3.12 & 2.65 & 2.87 & 2.95 & 1.96 & 2.37 & 2.65 \\
\hline$h_{\text {max }}(\mathrm{nm})$ & 442 & 445 & 450 & 444 & 449 & 453 & 458 & 469 & 481 \\
\hline$H(\mathrm{GPa})$ & 2.6 & 2.64 & 2.68 & 2.57 & 2.62 & 2.67 & 2.44 & 2.51 & 2.6 \\
\hline$E_{\mathrm{B}}(\mathrm{GPa})$ unloading & 43.53 & 44.35 & 44.82 & 43.53 & 44.06 & 44.46 & 39.66 & 40.95 & 41.64 \\
\hline$E_{8}(\mathrm{GPa})$ Hertzian & 41.8 & 42.73 & 43.35 & 40.82 & 41.64 & 42.26 & 34.91 & 37.95 & 40.28 \\
\hline
\end{tabular}



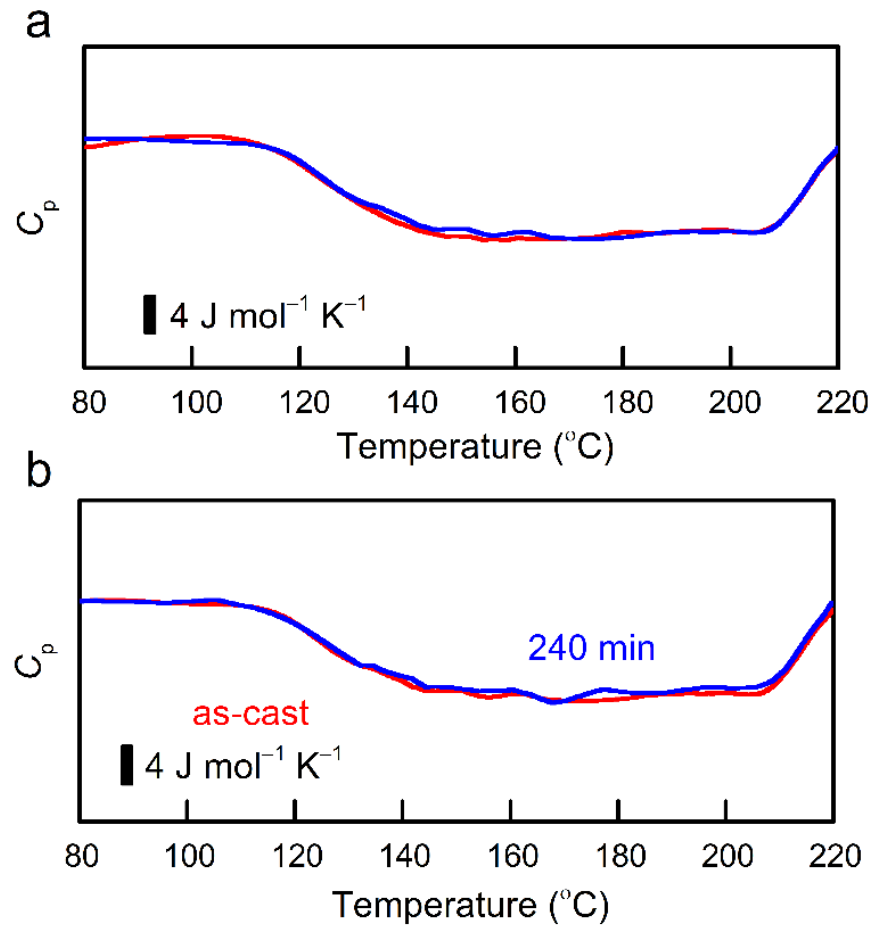

Extended Data Figure 1 | DSC traces for ribbons of $\mathrm{La}_{55} \mathrm{Ni}_{20} \mathrm{Al}_{25}$ glass (heated at $20 \mathrm{~K} \mathrm{~min}^{-1}$ ). (a) These example traces for as-cast samples show the exotherm, just below the glass-transition temperature, from which the heat of relaxation $\Delta H_{\text {rel }}$ is determined. (b) The effect of holding at 77 $\mathrm{K}$ : the traces show that the heat of relaxation $\Delta H_{\text {rel, }}$ given by the exotherm just below the glasstransition temperature, is, within the experimental error of $4 \%$, the same for an as-cast ribbon, and for a sample held for $4 \mathrm{hr}$ at $77 \mathrm{~K}$.

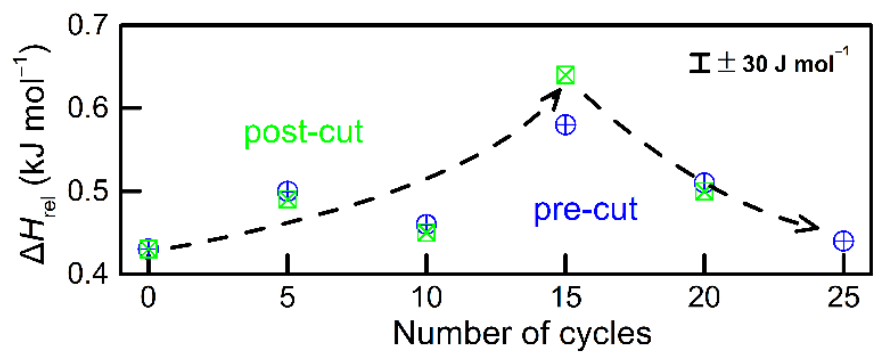

Extended Data Figure 2 | Differential scanning calorimetry (DSC) of $\mathrm{La}_{55} \mathrm{Ni}_{10} \mathrm{Al}_{35}$ bulk metallic glass. The heat of relaxation $\Delta H_{\text {rel }}$ is compared for discs (250-500 $\mu \mathrm{m}$ thick) pre-cut from the bulk rod and then treated with RT-77K cycles, and for discs post-cut from treated rod samples. There is no difference between these cases within the error of $\pm 30 \mathrm{~J} \mathrm{~mol}^{-1}$. 


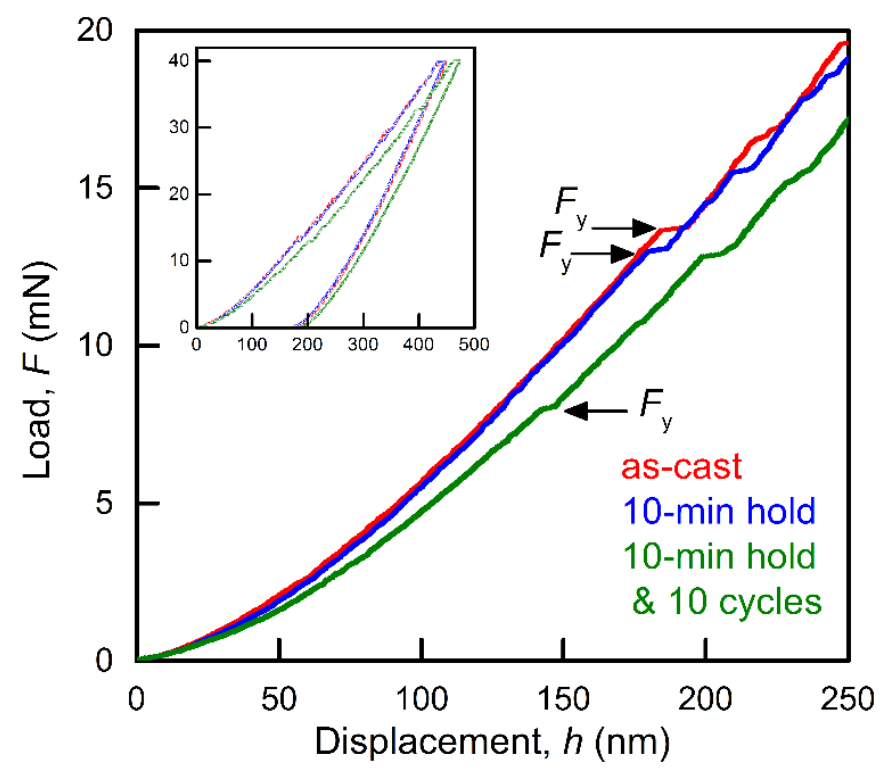

Extended Data Figure 3 | Load-displacement curves for ribbons of $\operatorname{La}_{55} \mathrm{Ni}_{20} \mathrm{Al}_{25}$ metallic glass tested up to a maximum load $\boldsymbol{F}_{\max }$ of $\mathbf{4 0} \mathrm{mN}$. The initial yield load $F_{\mathrm{y}}$ is indicated on the curves for the glass in three states: as-cast, after a 10-min hold at $77 \mathrm{~K}$, and after a further ten RT-77K cycles each with 1-min hold. 

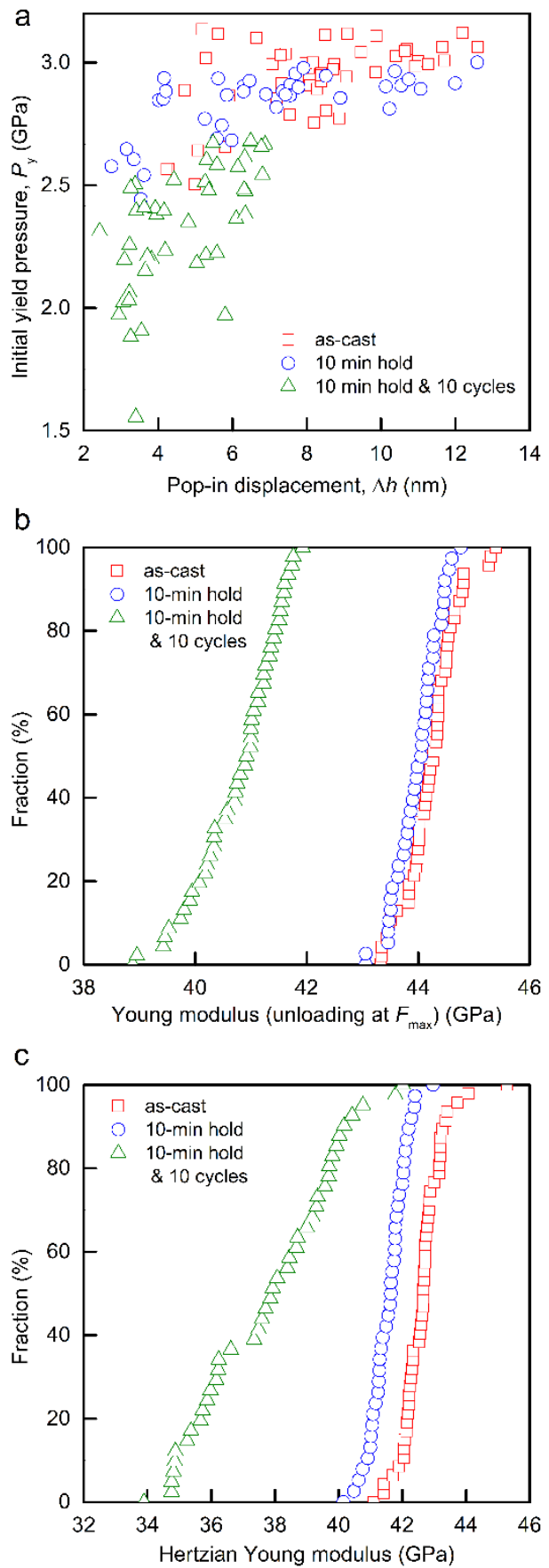

Extended Data Figure 4 | Instrumented indentation of $\mathrm{La}_{55} \mathrm{Ni}_{20} \mathrm{Al}_{25}$ metallic glass ribbon. (a) Initial yielding, characterized by initial yield pressure $P_{\mathrm{y}}$ and initial yield displacement Qh . Indentations are made for three states of the sample: as-cast, after a 10-min hold at $77 \mathrm{~K}$, and after a further ten RT77K cycles each with 1-min hold. (b,c) Distributions of the Young modulus, using data from the same indentations of the sample in three states as in Fig. 3 and in (a). Values of the Young modulus in the glass $E$ are determined (b) by the standard Oliver and $\mathrm{Pharr}^{36}$ method on unloading from $F_{\max }$ and (c) from Hertzian fitting to the $F-h$ curve up to the first pop-in. 


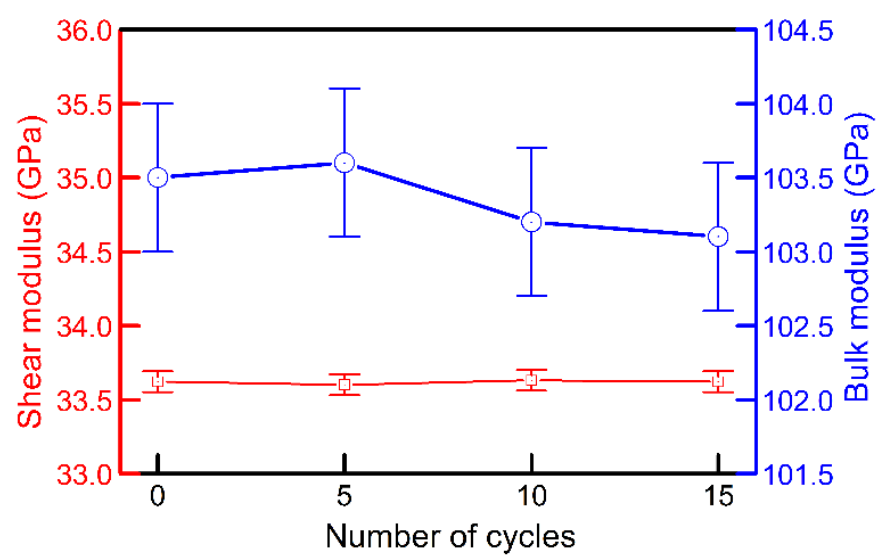

Extended Data Figure 5 | Elastic moduli derived from resonant ultrasound spectroscopy for $\mathrm{Cu}_{46} \mathrm{Zr}_{46} \mathrm{Al}_{7} \mathrm{Gd}_{1}$ BMG treated with RT-77K thermal cycles: shear modulus (left axis); bulk modulus (right axis). The bars correspond to root mean square errors in the fitted frequencies.
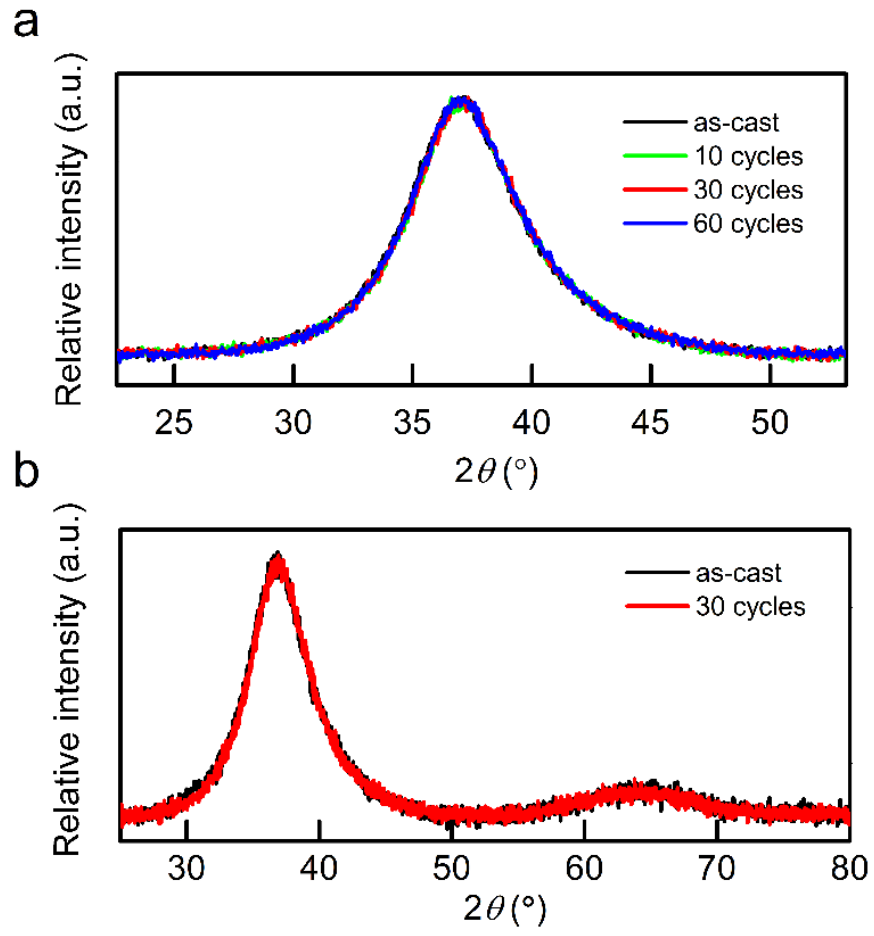

Extended Data Figure 6 | X-ray diffraction traces for Zr-based metallic glasses subjected to 338K77K thermal cycles. (a) for melt-spun ribbons of $\mathrm{Zr}_{61.1} \mathrm{Cu}_{26.3} \mathrm{Fe}_{2.1} \mathrm{Al}_{10.5}$; (b) for rods of $\mathrm{Zr}_{62.2} \mathrm{Cu}_{23.9} \mathrm{Fe}_{4.8} \mathrm{Al}_{9.1}$. No clear changes are induced by the cycling treatments. 


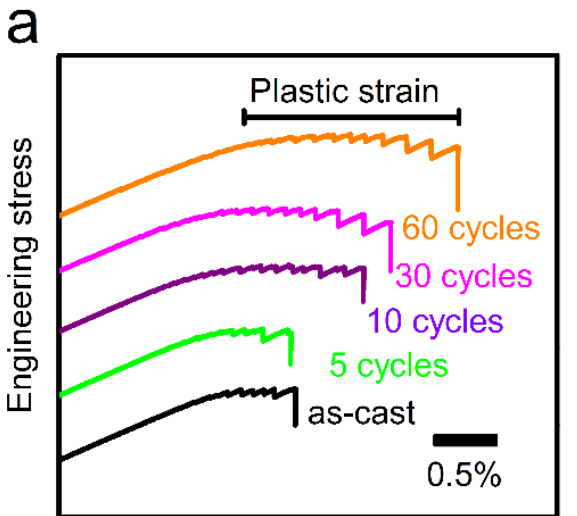

Engineering strain

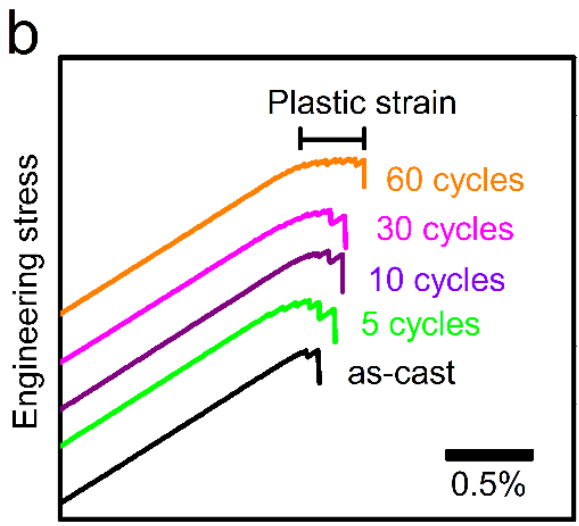

Engineering strain

Extended Data Figure 7 | Compressive stress-strain curves for rod samples of $\mathrm{Zr}_{62} \mathrm{Cu}_{24} \mathrm{Fe}_{5} \mathrm{Al}_{9} \mathrm{BMG}$.

(a) for rods of $2 \mathrm{~mm}$ diam.; (b) for rods of $2.5 \mathrm{~mm}$ diam. In each case, increasing numbers of 338K$77 \mathrm{~K}$ thermal cycles cause the plastic strain to increase.

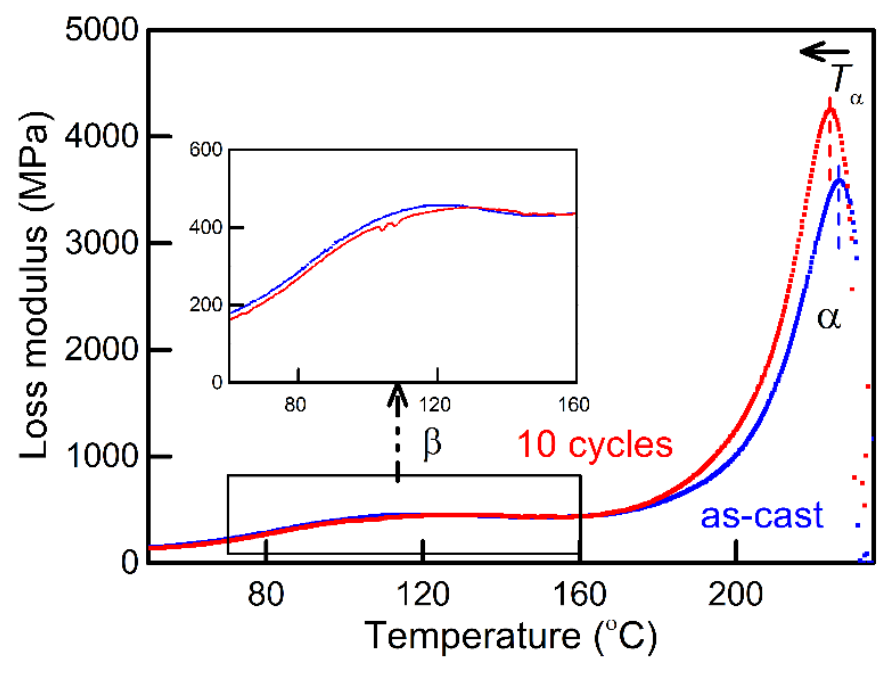

Extended Data Figure 8 | Dynamic mechanical analysis of ribbons of $\mathrm{La}_{55} \mathrm{Ni}_{20} \mathrm{Al}_{25}$ metallic glass. The heating rate is $3 \mathrm{~K} \mathrm{~min}^{-1}$. The general form of the curve matches that shown in Fig. 1a, where an example was chosen of a metallic glass showing $\beta$ relaxation at a particularly low value of $T / T_{\mathrm{g}}$. For $\mathrm{La}_{55} \mathrm{Ni}_{20} \mathrm{Al}_{25}$ the $\beta$ relaxation is centred at $T / T_{\mathrm{g}} \approx 0.8$. 